\title{
RESPOSTA DA FIGUEIRA (Ficus carica L.) AO USO DA IRRIGAÇÃO E NITROGÊNIO NA REGIÃO DE ILHA SOLTEIRA ${ }^{1}$
}

\author{
F.B.T. HERNANDEZ; M.A. SUZUKI²; S. BUZETTI; L.S. CORREA \\ Faculdade de Engenharia/UNESP - C.P. 31, CEP: 15378-000 - tha Solleira,SP
}

\begin{abstract}
RESUMO: Com o objetivo de avaliar a resposta da cultura da figueira (safra 91/92) à aplicação de làminas de irrigação e adubação nitrogenada realizou-se um experimento com seis laminas de irrigação $(0,25,50,75,100$ e $125 \%$ da evaporação do Tanque Classe $A)$ e seis níveis de nitrogênio $(0,150,300,450,600$ e $750 \mathrm{~g} / \mathrm{planta}$, instalado de acordo com um delineamento de blocos casualizados, em um esquema de parcelas sub-divididas, com quatro repetiçōes. Com base ma ańlise estatística realizada, verificou-se efeito significativo da irrigaçāo sobre a produtividade de frutos maduros, produtividade total, comprimento de ramos e altura e diâmetro de frutos maduros. A adubaçāo nitrogenada mostrou efeito significativo sobre a produtividade de frutos maduros e comprimento de ramos.

Descritores: figo, irrigação, nitrogênio.
\end{abstract}

\section{RESPONSE OF FIG-TREE ORCHARD (Ficus carica L.) UNDER IRRIGATION AND NITROGEN LEVELS AT THE ILHA SOLTEIRA (SP) REGION}

ABSTRACT: The study had the purpose of evaluating the effects of irrigation and nitrogen fertilization levels upon fig-tree onchards (harvest 1991/1992). A randomized split-plot block design was installed with six irrigation levels $(0,25,50,75,100$ and $125 \%$ of Class $A$ Pan Evaporation) and six nitrogen levels $(0,150,300,450,600$ and 750 $\mathrm{g} / \mathrm{plant}$ ), with four repetitions. According to the statistical analysis, significant effects of water supply were verified on ripe fruit harvest, total productivity, branch lenght and ripe fruit heigth and diameter. Nitrogen fertilization effects on ripe fruit harvest and branch lenght were also detected.

Key Words: fig-tree, irrigation, nitrogen.

\section{INTRODUÇÃO}

A cultura da figueira (Ficus carica L.) tradicionalmente plantada na região de Valinhos, Estado de São Paulo, vem atualmente apresentando uma anomalia de causa ainda desconhecida, obrigando alguns produtores a erradicarem seus pomares. Assim, estudos visando a implantação da cultura em outra região edafoclimática têm sido conduzidos por HERNANDEZ et al. (1991), HERNANDEZ et al. (1992a) e HERNANDEZ et al. (1992b) mostrando sua boa adaptação à região de Ilha Solteira, Estado de São Paulo. FACHINELLO et al. (1979), informa que pouco se sabe sobre a exigência da figueira em elementos nutritivos. Ainda esse autor relata que praticamente não existem regras especiais a esse respeito. As poucas experiências existentes parecem indicar que a figueira responde de forma muito favorável às aplicações de matéria orgânica no solo, tanto na forma de estrume curtido como na forma de adubação verde. TEIXEIRA \& CARVALHO (1978) concluíram que a adubação nitrogenada tem se mostrado benéfica para a produção da figueira. No entanto FACHINELLO et al. (1979) afirmam que o excesso de nitrogênio provoca desenvolvimento vigoroso e frutos maiores, porém retarda a maturação dos mesmos. Estes autores estudando os efeitos do nitrogênio, fósforo e potássio na cultura, não encontraram diferenças significativas quanto a produção total de figos verdes. De acordo com BATAGLIA et al. (1985),

\footnotetext{
${ }^{3}$ Trabalho desenvolvido com apoio financeiro da FAPESP. Projeto 89/3242-4.

2 Bolsista da FAPESP.
} 
postula-se que a adubação nitrogenada deva desempenhar importante papel não só pelo acúmulo de metab6́litos nitrogenados, mas também afetando a incorporação de assimilados através do aumento da capacidade fotossintética da planta.

Com relação à irrigação, a literatura não fornece muitas informações específicas da resposta desta cultura. OLITTA et al. (1979) desenvolveram experimento de irrigação com a cultura da figueira em Piracicaba-SP, o qual permitiu salientar os seguintes pontos: em condições de irrigação suplementar, a irrigação proporcionou, em média, um aumento de $10,6 \%$ na produção em peso e $3,2 \%$ no número de frutos por ha; a relação entre a produção e o fator $K$ de evaporação do Tanque Classe A, seguiu uma relação linear dentro da faixa de $K=0,4$ a 1,2 indicando que o estudo deveria ter sido realizado com uma amplitude maior de variação neste fator $e$, os resultados obtidos nos 2 primeiros anos na produção de figo, sugerem 0 fator $K$ de evaporação entre 0,4 e 0,8 para qualquer das frequências de irrigação estudadas, seja três ou uma vez por semana. Contudo, salientou-se no experimento o tratamento utilizando $\mathrm{K}=0,4$ e a frequência de irrigação de uma vez por semana.

Esse tratamento proporcionou em média um aumento de $19,4 \%$ na produção em peso dos frutos e de $14,6 \%$ no número de frutos por ha, em comparação com os tratamentos sem irrigação. SAMPAIO et al. (1981), conduziram experimento na região de Piracicaba, utilizando irrigação por gotejamento e três épocas de podas (março, agosto, dezembro) e constataram que é viável combinar a prática da irrigação com diferentes épocas de poda, visando a produção de frutos fora da época normal.

Esta prática deverá ser exequível em locais onde as temperaturas de inverno sejam menos rigorosas, como é o caso da região de Ilha Solteira.

HERNANDEZ et al. (1992b) estudando o efeito de 6 lâminas hídricas e 6 níveis de nitrogênio na produtividade da figueira (Ficus carica L.) verificaram que somente as lâminas hídricas influenciaram negativamente a produtividade de frutos maduros, evidenciando uma tendência de diminuição na produtividade com o aumento das lâminas hídricas, porém com o emprego do tratamento de $50 \%$ da ECA observaram aumentos de 10,8 e $11 \%$ sobre a produção de frutos maduros, produtividade total e número de frutos maduros/planta, respectivamente, quando comparado com o tratamento sem irrigação.

\section{MATERIAL E METODOS}

O presente experimento foi instalado na área experimental da Faculdade de Engenharia de Ilha Solteira - UNESP, localizada no encontro aproximado das coordenadas geográficas $20^{\circ} 22^{\prime}$ de Latitude Sul e $51^{\circ} 22^{\prime}$ de Longitude Oeste de Gr., com altitude ao redor de $335 \mathrm{~m}$, no município de Selvíria-MS. Segundo a classificação de KÖPPEN, o clima da região é do tipo Aw, apresentando uma temperatura média anual de $25^{\circ} \mathrm{C}$ e uma precipitação total anual de $1330 \mathrm{~mm}$ (CENTURION, 1982).

O solo da área foi classificado como Latossolo Vermelho Escuro, textura argilosa, conforme DEMATTÊ (1980) e a análise química do solo realizada antes da instalação do experimento apresentou os seguintes valores: $\mathrm{pH}\left(\mathrm{CaCl}^{2}\right)=4,3, \mathrm{M} . \mathrm{O} .=2,8 \%, \mathrm{P}($ resina $)=72$ $\mu \mathrm{g} / \mathrm{cm}, \mathrm{K}, \mathrm{Ca}, \mathrm{Mg}, \mathrm{H}+\mathrm{Al}, \mathrm{S}, \mathrm{T}$, respectivamente $0,18,1,7,0,9,6,03,2,78,8,81 \mathrm{meq} / 100 \mathrm{~cm}$ e $\mathrm{V}=32 \%$.

A figueira utilizada foi a variedade Roxode-Valinhos, obtida através da propagação assexual por meio de estacas. Comercialmente, esta variedade é a única explorada no Estado de São Paulo. As outras, como Pingo de Mel, Nóbile e Negro Largo não apresentaram nenhum interesse. A planta é vigorosa, produtiva e adapta-se muito bem ao sistema de poda drástica ou enérgica. A variedade se presta para a produção de figos maduros para o consumo "in natura" e ainda para a produção de figos tipo industrial verde, inchados e maduros ou rami (FRANCO \& PENTEADO, 1986). Essa variedade é a mais cultivada nas regiōes produtoras do país, apresentando boa produtividade e frutos de ótima qualidade, tanto para consumo "in natura" como para processamento industrial (RIGITANO \& OJIMA (1963), SIMÃO (1971) e GOMES (1975)). O plantio das mudas enraizadas no campo foi realizado em 19 de maio de 1988 espaçadas em 3,0 metros entre linhas e 2,0 metros entre plantas na linha.

Após o plantio no campo, as mudas foram conduzidas de acordo com as recomendações de PEREIRA (1981), sendo que para o presente experimento as plantas se apresentavam com doze ramos e em sua terceira colheita.

Para o presente experimento não se utilizou cobertura morta, fazendo-se necessário a aplicação de herbicida para o controle de plantas invasoras. Periodicamente foi feita a eliminação de brotos ao 
longo dos ramos, de modo a manter os ramos sem brotações laterais.

O sistema de irrigação utilizado foi do tipo microaspersão, de fabricação nacional. Foi instalado um microaspersor para cada duas plantas e a irrigação foi praticada 3 vezes por semana. A precipitação média de cada microaspersor foi 1,9 $\mathrm{mm} / \mathrm{h}$ (raio de $2,4 \mathrm{~m}$ ), a uma pressão de 2,5 $\mathrm{kgf} / \mathrm{cm}^{2}$ logo após o filtro de tela, apresentada em testes antes do início do experimento.

As adubações de cobertura foram feitas nos dias 25 de julho (no início da brotação) e 01 de outubro de 1991, utilizando-se superfosfato simples e cloreto de potássio. As doses totais de superfosfato simples e cloreto de potássio foram respectivamente 222 e $120 \mathrm{~g}$ por planta, aplicadas em circunferência completa às plantas.

Foram utilizados seis tratamentos principais, estabelecidos com base na evaporação do Tanque Classe A (ECA), sendo LO = sem irrigação, $\mathrm{L} 1=0,25 \mathrm{ECA}, \mathrm{L} 2=0,50 \mathrm{ECA}, \mathrm{L3}=$ $0,75 \mathrm{ECA}, \mathrm{L4}=\mathrm{ECA}, \mathrm{L5}=1,25 \mathrm{ECA}$, e seis tratamentos secundários. Estes constituíram-se de seis doses de nitrogênio: $\mathrm{NO}=0, \mathrm{~N} 1=150, \mathrm{~N} 2$ $=300, \mathrm{~N} 3=450, \mathrm{~N} 4=600, \mathrm{~N} 5=750 \mathrm{~g} / \mathrm{planta}$, parcelados em 5 vezes, de agosto a dezembro de 1990 , em intervalos mensais.

O nitrogênio foi aplicado na forma de sulfato de amônio e também em circunferência completa às plantas.

$O$ delineamento experimental adotado foi 0 de blocos casualizados em um esquema de parcelas sub-divididas, com 6 tratamentos principais e 6 tratamentos secundários, com 4 repetições. A área útil de cada sub-parcela foi de $12 \mathrm{~m}$, contendo 2 plantas úteis.

Segundo o esquema apresentado teve-se para cada linha (parcela), 6 sub-parcelas, cada qual constituída de 3 plantas, sendo duas utilizadas para amostragens e uma como bordadura. Os parâmetros avaliados neste experimento foram:

Produção de frutos: A colheita de frutos foi realizada em duas plantas por sub-parcela, sendo que a colheita dos frutos maduros teve início em 30 de outubro de 1991 encerrando-se em 18 de março 1992. A colheita dos frutos verdes foi realizada também em 18 de março de 1992.

Número e tamanho de frutos: Em cada colheita foi efetuada a contagem do número de frutos maduros e suas dimensões (altura e diâmetro), estas feitas através de uma calha graduada. Desse modo estão sendo apresentados neste trabalho valores correspondentes à média da safra, sendo seu valor determinado pela soma dos valores obtidos em cada colheita, dividido pelo número de frutos.

Peso médio de frutos e comprimento médio de ramos: $O$ valor apresentado corresponde ao valor médio ao longo da safra, este calculado pela somatória dos valores obtidos em cada colheita, dividido pelo número total de frutos.

As leituras de comprimento dos ramos foram efetuadas no dia 29 de janeiro de 1992 e representam a média de duas plantas por subparcela.

\section{RESULTADOS E DISCUSSÃo}

Na TABELA 1 encontram-se os resultados da análise de variância e médias para os parâmetrós avaliados. Nesta tabela são apresentados os resultados do teste $F$, da análise de variância preliminar, da análise de regressão e também as equações de regressão, quando significativas, e sempre a de maior grau. Pelo teste $F$, as lâminas hídricas influenciaram significativamente a produtividade de frutos maduros e a produtividade total. A produção e produtividade de frutos verdes foram influenciadas pelos níveis de nitrogênio.

Através da análise de regressão verificou-se que as lâminas hídricas influenciaram tais parâmetros com os dados se ajustando a uma função matemática de segundo grau. Sendo que o ponto de máxima para a produtividade de frutos maduros foi atingido com lâmina de $1787 \mathrm{~mm}$ (Figura 1).

OLITTA et al. (1979), em condições de irrigação suplementar, verificaram que houve em média um aumento de $10,6 \%$ na produção em peso e 3,2\% no número de frutos/ha, enquanto que neste trabalho foram obtidos com a aplicação de $1461 \mathrm{~mm}$ ( $50 \%$ da ECA) aumentos de $1.224 \%$ e $468 \%$ sobre a produção de frutos maduros e produtividade total, respectivamente, quando comparado ao tratamento sem irrigação. HERNANDEZ et al. (1992b) verificaram com a utilização do tratamento de $50 \%$ da ECA, aumentos de $10 \%, 8 \%$ e $11 \%$ sobre a produção de frutos maduros, produtividade total e número de frutos/planta, respectivamente, também quando comparado ao tratamento sem irrigação, portanto apenas dependendo das chuvas. HERNANDEZ et al. (1991) obtiveram apenas 8\% de acréscimo na produtividade total de frutos quando da utilização da irrigação suplementar, em comparação com a cultura não irrigada. 
TABELA 1 - Valores de F, coeficientes de variação e médias obtidas para os parâmetros: produtividade (kg/ha) de frutos maduros, verdes e total, comprimento de ramos $(\mathrm{cm})$ e peso médio $(\mathrm{g})$ de frutos maduros.

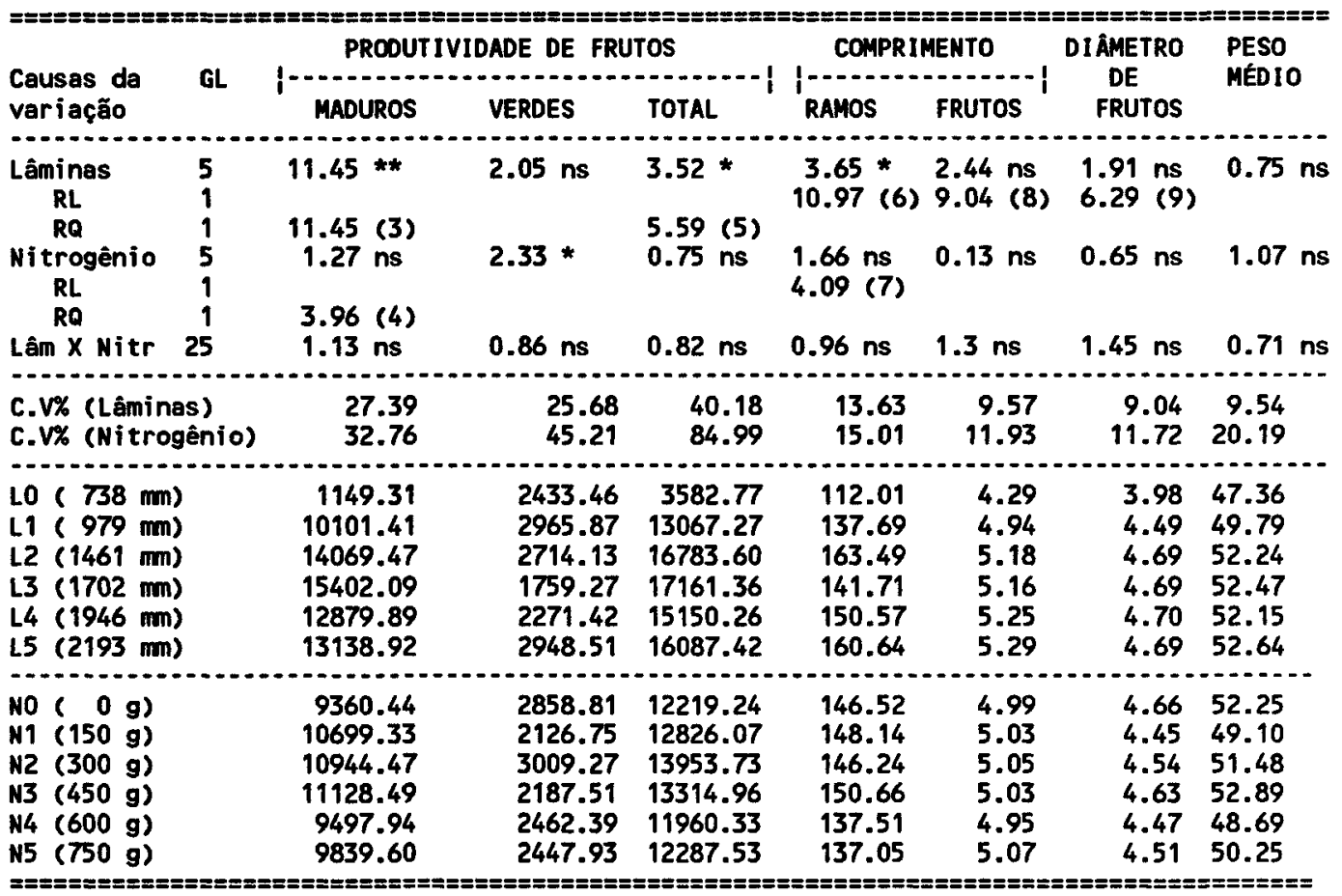

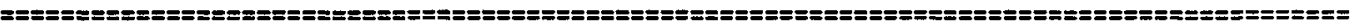
ns $=$ nao significativo

$*=$ significativo a $5 \%$ de probabilidade

** = significativo a $1 \%$ de probabilidade

RL $=$ Regressão linear

$R Q=$ Regressão quadratica

(1) $\mathrm{Y}=-0.00000565 \mathrm{X}^{2}+0.0202023 \mathrm{X}-9.964926$

$\mathrm{R} 2=0.77 * *$

(2) $Y=-0.00000595 X^{2}+0.0043433 X+5.744881$

$\mathrm{R} 2=0.63 *$

(3) $Y=-0.00942107 X^{2}+33.6706419 X-16608.243970$

$\mathrm{R} 2=0.77 * *$

(4) $Y=-0.00991184 X^{2}+7.2387716 X+9574.820323$

$\mathrm{R} 2=0.63 *$

(5) $Y=-0.01285295 X^{2}+44.1959484 X-20380.983502$

$\mathrm{R} 2=0.89 *$

(6) $Y=0.0259713 X+105.315414$

(7) $Y=-0.0142480 X+149.695437$

$\mathrm{R} 2=0.60 * *$

(8) $Y=0.0005752 X+4.154746$

$\mathrm{R} 2=0.49 *$

(9) $\mathrm{Y}=0.0004103 \mathrm{X}+3.924973$

$\mathrm{R} 2=0.74 * *$

$\mathrm{R} 2=0.66 *$

Verifica-se que neste trabalho houve aumentos mais expressivos com relação à produção e produtividade de frutos. Isto se deve ao fato de que neste experimento não se utilizou cobertura morta na cultura, que desempenha papel fundamental na retenção da umidade do solo. Os resultados apontam para uma necessidade da adoção obrigatória de tal prática, quando da ausência de equipamentos de irrigação. Verificou-se um atraso na emissão de brotações pelas plantas não irrigadas, proporcionado pela ausência de chuvas, repercutindo diretamente na produtividade de frutos. 


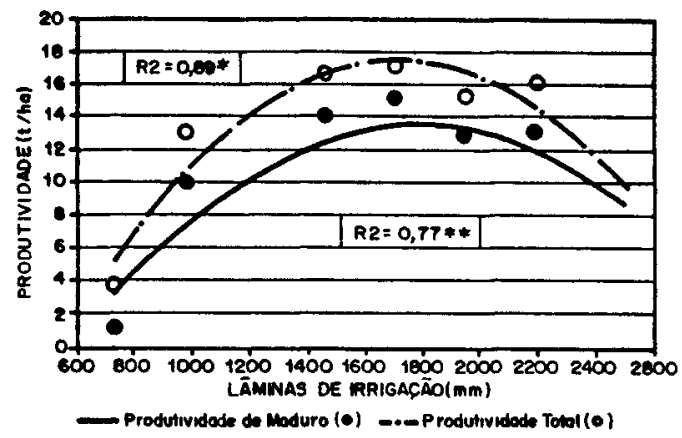

Figura 1 - Efeito de lâminas sobre a produtividade de frutos maduros e produtividade total de figo.

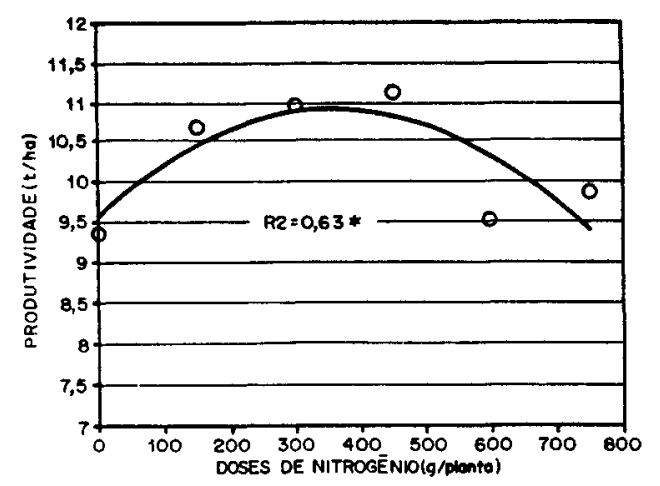

Figura 2 - Efeito de doses de nitrogênio na produtividade de frutos maduros de figo.

A variável, doses de nitrogênio, influenciou apenas a produção e produtividade de frutos verdes, porém não se ajustando a nenhuma função matemática. Com relação à produção e produtividade de frutos maduros, pela análise de regressão este parâmetro foi influenciado pelas doses de nitrogênio ajustando-se a uma função exponencial quadrática, com ponto de máxima sendo atingido com dose de $365 \mathrm{~g} /$ planta (Figura 2).

As lâminas hídricas influenciaram significativamente o parâmetro comprimento de ramos, ajustando-se a uma função linear de modo que seu valor aumentou com o aumento das lâminas hídricas empregadas, porém PEDROTTI et al. (1983) trabalhando com cinco lâminas hídricas verificaram que, com relação a este parâmetro, houve um ajuste de regressão quadrática. Estes resultados provavelmente podem ser atribuídos a diferenças edafoclimáticas às quais foram submetidos os trabalhos, principalmente clima.

Para o presente experimento ficou bastante evidente o efeito das lâminas hídricas sobre o desenvolvimento da cultura, verificando resposta linear e crescente mesmo utilizando lâminas hídricas bem superiores às utilizadas pelo autor.

Outro fato que merece atenção $E$ a temperatura regional, uma vez que comparadas as temperaturas médias anuais, a região de Ilha Solteira apresenta uma média superior à região onde se desenvolveu o trabalho relatado pelo autor, o que é fundamental para o bom desenvolvimento da cultura. O contrário foi observado com a variável doses de nitrogênio. $O$ comprimento médio de frutos maduros se ajustou à regressão linear, em relação às lâminas hídricas, onde estas influenciaram positivamente, fazendo com que com o aumento das mesmas o comprimento dos frutos aumentasse. Para o parâmetro diâmetro de frutos, houve ajuste à regressão linear crescente em relação às lâminas hídricas. Porém com relação às doses de nitrogênio não houve resposta da cultura ao comprimento e diâmetro de frutos, portanto não se ajustando a nenhuma função matemática.

Segundo SIMÃO (1971), o excesso de nitrogênio provoca desenvolvimento vigoroso da planta e frutos maiores, porém retarda a maturação dos mesmos. No presente estudo isso não foi verificado.

As médias de comprimento de frutos variaram de 4,29 a $5,29 \mathrm{~cm}$ e diâmetro de 3,98 a $4,7 \mathrm{~cm}$, valores bem inferiores aos relatados por PEREIRA (1981), onde descreve frutos com comprimento de $7,5 \mathrm{~cm}$. Isto se deve provavelmente ao fato de que os estudos em questão foram realizados em regiões edafoclimáticas distintas, tendo a planta um comportamento característico para cada região. O parâmetro peso médio de frutos maduros ( $\mathrm{g}$ ) não foi influenciado pelas lâminas hídricas, bem como pelas doses de nitrogênio. As médias variaram de 47,36 a $52,64 \mathrm{~g}$, peso de frutos considerados relativamente bons, porém inferiores aos descritos por PEREIRA (1981) que relatou frutos com peso médio de 60 a $90 \mathrm{~g}$.

\section{CONCLUSÕES}

Com base nos resultados obtidos no presente experimento pode-se concluir que as lâminas hídricas proporcionaram efeito positivo na produtividade de frutos maduros, produtividade 
total, comprimento de ramos e comprimento e diâmetro de frutos maduros, enquanto que os níveis de nitrogênio também proporcionaram efeito positivo para produtividade de frutos maduros, apresentando como dose de máxima produtividade $365 \mathrm{~g}$ de $\mathrm{N} /$ planta, e efeito negativo no comprimento de ramos. O peso médio de frutos maduros não foi influenciado por nenhum dos fatores. A interação lâminas hídricas $x$ doses de nitrogênio, não proporcionou efeito significativo sobre nenhum parâmetro. Verificou-se a boa adaptação da cultura à região, mostrando-se favorável o cultivo da figueira, com frutos de boa qualidade e produtividade, evidenciando a importância da irrigação na ausência de cobertura morta.

Diante dos resultados apresentados, a aplicação de $75 \%$ da evaporação do Tanque Classe A seria a indicada para a região, fazendo-se a ressalva de que neste trabalho, a análise econômica não foi realizada.

Assim, a cultura da figueira pode ser considerada uma opção a mais aos agricultores na diversificação de suas culturas.

\section{AGRADECIMENTOS}

Os autores manifestam seus agradecimentos à FAPESP pelo apoio financeiro para a realização deste trabalho, bem como pela concessão de bolsa de estudos ao segundo autor.

\section{REFERÊNCIAS BIBLIOGRÁFICAS}

BATAGLIA, O.C.; QUAGGIO, J.A.; BRUNINI, O.; CIARELLI, D.M. A adubação nitrogenada e ajustamento osmótico em milho e sorgo. Pesquisa Agropecuária Brasileira, Brasilia, v.20, n.6, p.659-665, 1985.

CENTURION, J.F. Balanço hídrico na região de Iltha Solteira. Cientifica, Botucatu, v.10, n.1, p.57-61, 1982.

DEMATTÊ, J.L.I. Levantamento detalhado dos solos do Campus Experimental de Iha Solteira. Piracicaba, ESALQ, 1980. 114p. (Mimeografado)

FACHINELLO, J.C.; MANICA, I.; MACHADO, A.A. Resposta da figueira (Ficus carica L.) cv. São Pedro a dois niveis de adubação com nitrogênio, fósforo e potássio. In: CONGRESSO BRASILEIRO DE FRUTICULTURA, 5., 1979, Pelotas. Anais... Pelotas: Sociedade Brasileira de Horticultura, 1979, p.889-895.

FRANCO, J.A.M.; PENTEADO, S.R. Cultura da figueira. In: PENTEADO, S.R. Fruticultura de clima temperado em Săo Paulo. Campinas: Fundação Cargill, 1986. cap.5, p.113-129.
GOMES, R.P. Fruticultura brasileira. 2.ed. São Paulo: Nobel, 1975. 446p.

HERNANDEZ, F.B.T.; CORRÊA, L.S.; MODESTO, J.C.; YOKOTA, M.A. Efeitos de niveis de nitrogênio e da irrigação na cultura do figo. Revista Brasileira de Fruticultura, Cruz das Almas, v.13, n.4, p.211-216, 1991.

HERNANDEZ, F.B.T.; SUZUKI, M.A.; MODESTO, J.C.; CORREA, L.S. Efeitos de lâminas de irrigação e niveis de nitrogênio nos aspectos qualitativos e nutricionais do figo (Ficus carica L.). In: CONGRESSO BRASILEIRO DE ENGENHARIA AGRfCOLA, 21., 1992, Santa Maria. Anais... Santa Maria: Sociedade Brasileira de Engenharia Agrícola, 1992a. v.2B, p.862-874.

HERNANDEZ, F.B.T.; MODESTO, J.C.; YOKOTA, M.A.; CORREA, L.S.; ZOCOLER, J.L. Efeitos de lâminas de irrigação e níveis de nitrogênio sobre os principais parâmetros produtivos da cultura do figo (Ficus carica L.). In: CONGRESSO BRASILEIRO DE ENGENHARIA AGRfCOLA, 21., 1992, Santa Maria. Anais... Santa Maria: Sociedade Brasileira de Engenharia Agrícola, 1992a. v.2B, p.875-884

OLITTA, A.F.; SAMPAIO, V.R.; BARBIN, D. Estudo da lâmina e frequência da irrigação por gotejo na cultura do figo. $O$ Solo, Piracicaba, v.71, n.2, p.9-22, 1979 .

PEDROTTI, E.L.; MANICA, I.; BELTRAME, L.F.S. Niveis de irrigação, crescimento das plantas e concentração de nutrientes nas folhas de figueira (Ficus carica L.) Roxo-de-Valinhos. Agronomia Sulriograndense, Porto Alegre, v.19, n.1, p.103-116, 1983.

PEREIRA, F.M. Cultura da figueira. São Paulo: Livroceres, 1981. 73p.

RIGITANO, O.; OJMMA, M. Época de poda da figueira cultivada no Estado de São Paulo. Bragantia, Campinas, v.22, n.42, p.529-536, 1963.

SAMPAIO, V.R.; OLITTA, A.F.; OLIVEIRA, A.S. Efeito das épocas de poda na produção do figo irrigado por gotejamento. Anais da Escola Superior de Agricultura "Luiz de Queiroz", Piracicaba, v.38, p.847-857, 1981 .

SIMÃo, S. Manual de fruticultura. São Paulo, Agronômica Ceres, 1971. 530p.

TEXEERA, N.T.; CARVALHO, L.H. Alguns aspectos nutricionais da cultura da figueira (Ficus carica L.). 0 Solo, Piracicaba, v.71, n.3, p.3-5, 1978.

Enviado para publicação em 26.05 .93

Aceito para publicação em 06.10 .93 